\title{
CULTURA AUDIOVISUAL E ARTE CONTEMPORÂNEA
}

\author{
José Mario Ortiz Ramos \\ Professor do Departamento de Sociologia do IFCH da Unicamp \\ Maria Lucia Bueno \\ Professora do Mestrado em Comunicação da Universidade Anhembi Morumbi
}

\begin{abstract}
Resumo: Tendo como fio condutor a cultura audiovisual e as artes plásticas contemporâneas, procurou-se enfocar a reorganização da produção cultural no cenário globalizado, considerando particularmente a participação de dois fatores: as políticas culturais e as pesquisas acadêmicas.

Palavras-chave: cultura e globalização; cinema e televisão; arte contemporânea.
\end{abstract}

$\mathrm{N}$ o final do século XX, a produção cultural transformou-se num dos principais domínios da economia mundializada, sem que este fenômeno tenha derivado um estado de degradação cultural generalizada, conforme os prognósticos mais pessimistas de Theodor Adorno. Porém, o processo de consolidação da cultura em setor econômico, após os anos 60 , só veio a ser um empreendimento bem-sucedido, nos países ricos, graças à atuação conjunta do mercado com o Estado (Pommerehne e Frey, 1993). A gestão cultural do Estado na sociedade contemporânea ocorre de forma diversa dos momentos históricos anteriores, quando assumia um caráter intervencionista, procurando orientar e conduzir a organização da produção. Atualmente sua ação se mantém restrita ao papel de parceiro da cultura, fornecendo subsídios e suporte, sem interferir diretamente sobre os conteúdos.

A consolidação da cultura como um campo econômico foi um trabalho que envolveu políticas culturais, alterações nas legislações, criação de novos mecanismos fiscais e, sobretudo, aplicação de um volume de capitais considerável. Um caso exemplar é o da evolução do orçamento do Ministério da Cultura francês desde a gestão de Andre Malraux em 1968, quando girava em torno de 0,38\% do PIB, até a atual, de Catherine Tasca, que em 2001 atingiu a cifra de $0,98 \%$, representando a mais alta dotação para a cultura da história do país, envolvendo um capital de mais de 16 bilhões de francos. ${ }^{1}$ Ultimamente, se em países onde este mercado já está consolidado - como os Estados Unidos ou mesmo a França - alguns setores começam a colocar em questão o grande afluxo de capitais consumido pelo setor, trata-se de uma outra questão. Para a reflexão neste artigo, o que importa reter é que, de diferentes formas, com maior ou menor participação, o Estado aparece como parceiro na organização do campo da economia da cultura no contexto globalizado.

Foi nos Estados Unidos, na década de 30, durante a depressão econômica, que ocorreu o primeiro surto de expansão da cultura e das artes, particularmente da indústria cultural, que, apesar de ser um fenômeno norte-americano, adquiriu proporções internacionais. Em menor escala a questão entrou também para a pauta dos projetos do Estado e do mercado de parte dos países do mundo ocidental. A explosão da indústria cinematográfica em Hollywood e a emergência dos museus de arte moderna em Nova York e nas principais cidades dos Estados Unidos estão entre as expressões mais significativas deste processo no cenário norte-americano.

No pós-guerra, principalmente depois dos anos 60 , esse processo de expansão da cultura acentuou-se, levando inclusive a uma redefinição do papel da produção cultural na sociedade contemporânea, como também a uma reorganização das formas de gestão e organização dos domínios da cultura. Na base dessas transformações, pode- 
se mencionar o peso considerável de pelo menos dois fatores. O desenvolvimento do que Armand Mattelart (1994) designa sistema de comunicação mundo construiu uma nova base material, a partir da qual a vida, em diferentes partes do planeta, passa a evoluir num movimento de conexão crescente, desempenhando um papel determinante na ampliação da esfera da cultura.

Aliado a esse fenômeno, no âmbito da cultura contemporânea, houve uma multiplicação dos campos de produção em diferentes regiões do planeta, que redundou na desterritorialização da indústria cultural. Aquilo que até então era um fenômeno norte-americano com expressão internacional assumiu uma diversidade de configurações, que começaram a entrar em confluências e a se entrelaçar, com o desenvolvimento do sistema de comunicação, formando os fluxos que constituem o espaço cultural globalizado em que vivemos. O sistema de fluxos impõe uma dinâmica nova à realidade contemporânea e, através dele, os componentes se misturam aleatoriamente numa seqüência sem princípio e nem fim, que está em constante transformação. Alguns conteúdos adquirem mais visibilidade - seja por estarem ligados a tradições fortes, seja por contarem com um respaldo sólido da mídia, como é o caso das produções cinematográficas hollywoodianas que combinam as duas condições.

Em decorrência da influência desses dois fatores - o desenvolvimento do sistema de comunicação mundo e a desterritorialização da indústria cultural - tem-se uma expansão sem precedentes do universo da cultura, que termina transformando o setor numa das principais economias da sociedade globalizada. Essa mudança quantitativa implicou outras transformações de caráter qualitativo, trazendo redefinições ao papel da cultura num contexto social que se globaliza marcado por um crescimento acelerado da população do mundo.

Uma das mudanças qualitativas, relacionada com a questão da recepção, diz respeito ao fato de a arte e a cultura, após a década de 60 , terem se transformado de simples reduto de lazer numa das principais esferas de construção de identidade. Andreas Huyssen (1997:247) observa que, "sobretudo nas culturas ou subculturas juvenis, as identidades se adotam provisoriamente e se articulam mediante pautas de vida e complicados códigos subculturais. A atividade cultural em geral não é mais encarada como algo que ofereça descanso e compensação (..) O crescimento e a proliferação da atividade cultural são melhor interpretados como um agente da modernização, representante de uma nova etapa da sociedade de consumo."
Outra mudança referente à esfera da produção cultural está intimamente relacionada com os redirecionamentos da função da cultura no âmbito da recepção. Desde o final da Segunda Guerra Mundial, a produção cultural e artística não pode mais ser encarada apenas do ponto de vista do entretenimento ou do prazer estético. A partir de então, fica patente uma das principais vocações da cultura e da arte moderna desde o final do século XIX, que é a de se tornarem espaços que trazem à tona problemáticas importantes do mundo contemporâneo, que podem ser tanto de ordem local como universal, discorrendo sobre temáticas muito variadas que abarcam tanto a esfera pública quanto o domínio da intimidade.

No final dos anos 70, teve início uma nova revolução no domínio da indústria cultural, desta vez no âmbito da tecnologia. Um novo aparato tecnológico, até então de difícil manipulação e de alto custo, tornou-se acessível ao uso doméstico, introduzindo transformações nas relações das pessoas com o universo audiovisual. Esse fenômeno é responsável por uma nova reorientação no mundo da cultura. Os aparelhos mais econômicos e de fácil manipulação transformam todo receptor num produtor virtual. Com isso, tem-se uma nova forma de desterritorialização da produção audiovisual: para além das fronteiras dos grandes estúdios e das grandes gravadoras. Nos anos 80 e 90 , houve uma ampliação considerável do número de produtores que conseguiram entrar no mercado utilizando a tecnologia doméstica. $\mathrm{O}$ campo das artes plásticas também foi afetado, com os artistas incorporando em suas produções os recursos audiovisuais, modificando o próprio universo material do artista plástico.

Outra mudança mais radical, ainda associada à tecnologia, diz respeito ao próprio processo de recepção, que passou por grandes transformações com o uso corrente de aparelhos como o videocassete, as câmeras de vídeo e, mais recentemente, os microcomputadores. Manuel Castells (2000) observa que, a partir de então, a audiência deixou de ser objeto passivo para se tornar sujeito interativo. As pessoas "começaram a filmar seus eventos, de férias a comemorações familiares, assim produzindo as próprias imagens, além do álbum fotográfico. Apesar de todos os limites dessa autoprodução de imagens, tal prática realmente modificou o fluxo de mão única das imagens e reintegrou a experiência de vida e a tela" (Castells, 2000:363). Conseqüentemente, houve uma complexificação do fluxo e uma intensificação da segmentação da recepção no domínio da cultura de massa. Seria o que Nestor Garcia Canclini (1997:304) designa como 
descolecionamento: “As culturas já não se agrupam mais em grupos fixos e estáveis (...) Agora as coleções renovam sua composição e sua hierarquia com as modas, entrecruzam-se o tempo todo, e, ainda por cima, cada usuário pode fazer sua própria coleção. As tecnologias de reprodução permitem a cada um montar em sua casa um repertório de discos e fitas que combinam o culto com o popular, incluindo aqueles que já fazem isso na estrutura das obras."

Com a globalização, as imagens e os conteúdos culturais passam a circular e interagir em escala planetária, transformando o espaço da cultura de massa (compreendida como ampliação do público) e da indústria cultural num domínio da diversidade e da heterogeneidade, mesmo que elas ainda dependam de formatos e padrões para serem veiculadas. No entanto, estes padrões vêm se revelado cada vez mais flexíveis, com um grande potencial para incorporar as inovações.

A partir de então verificou-se - nos países ricos - um aumento da atuação do Estado na área, fomentando o crescimento do setor cultural, sem deixá-lo inteiramente ao sabor do mercado em globalização, procurando fornecer respaldo aos núcleos de produção nacionais. Esta atuação do Estado, na maior parte dos países onde se concretizou, viabilizou-se embasada em extensas pesquisas no setor, que levaram a uma expansão da sociologia da cultura, da comunicação, das artes e, posteriormente, dos estudos econômicos aplicados a esses domínios.

O aumento deste campo de estudos nas últimas décadas se deu em decorrência de dois fatores. O primeiro está ligado à ampliação do público, do mercado de bens simbólicos e da importância do setor na sociedade, que o transformou em alvo privilegiado dos pesquisadores. Este crescimento sem precedentes da área levou, como já mencionado, a uma reorganização do mundo da cultura e das artes, implicando também redefinições das formas de gestão pública e privada nesse domínio. Os novos desafios derivados das mudanças, que abarcam desde a ampliação e a segmentação do público, até a redefinição das fronteiras tradicionais - entre o alto e o baixo - que haviam configurado este universo, geraram uma série de pesquisas acadêmicas formuladas a partir de demandas específicas do setor, que se transformaram em base de informação para as estratégias de atuação nesse campo.

$\mathrm{O}$ fenômeno acarretou duas transformações fundamentais. Através das políticas estatais, houve um crescimento da participação dos intelectuais no desenvolvimento do campo cultural, exemplificando bem o que Anthony
Giddens (1990) designa como o papel reflexivo de ciências, tais como a sociologia e a economia, na constituição da sociedade contemporânea. A segunda transformação importante foi a reestruturação, a partir de então, do debate intelectual em torno da questão da cultura e da comunicação. Até os anos 60 e 70, o campo intelectual, na sua maior parte, atuava com uma autonomia considerável, se contrapondo ao campo empírico das pesquisas de mercado. Nesse universo, disciplinas ligadas à estética e à semiologia tendiam a dar o tom nos estudos. Com a ampliação das pesquisas acadêmicas geradas pelas demandas governamentais e privadas, desenvolveu-se uma nova área, fundada na sociologia, na história e, posteriormente, na economia, que tem como principal objetivo mapear os campos de produção e recepção, procurando identificar a dinâmica de seu funcionamento, apoiando-se em extensas pesquisas empíricas. A propósito, Bernard Miége (1999:37) observa: "Na França as pesquisas em comunicação se orientaram desde cedo para o estudo das indústrias da cultura e da informação dentro de perspectivas que misturam as aproximações econômicas e sociopolíticas, mesmo as geopolíticas, com a preocupação, apesar das diferenças entre os autores, de ultrapassar visões muito unilaterais como as da Escola de Frankfurt ou as análises do Imperialismo cultural."

Focando o caso francês, observa-se que, a partir dos anos 70, houve uma multiplicação de institutos de pesquisa e instituições de fomento à produção cultural operando em estreita cooperação com o Estado (Pineau, 1999; Moulin, 1992; Domínguez e Morató, 1991). Um exemplo é a constituição de um organismo como o $L a$ Documentation Française, que centraliza as pesquisas governamentais, contemplando uma gama ampla de setores (cultura, saúde, política internacional, etc.) e congregando, no interior de cada área, diferentes núcleos de pesquisa. O curso destas pesquisas vem se desenvolvendo em consonância com as direções imprimidas às políticas culturais.

No decorrer dos anos 70 e 80, por exemplo, as pesquisas no setor cultural de um modo geral contemplaram prioritariamente aspectos relacionados à produção e à criação. Na década de 90 , houve um crescimento das pesquisas de recepção. Esta mudança de rumo está associada a uma alteração de orientação das políticas culturais, relacionada com a segmentação do público. Se até a gestão de Jack Lang, no governo François Mitterrand, elas se concentravam no âmbito da criação cultural, atualmente a tendência é de, cada vez mais, canalizar os esforços para atrair 
diferentes segmentos do público, concentrando uma parte substantiva dos recursos na construção da recepção (Telerama, 2000b).

A seguir, a abordagem enfoca o tema a partir de dois domínios específicos: a cultura audiovisual e a arte contemporânea, sendo que em ambos continua-se a privilegiar o contexto francês.

\section{CULTURA AUDIOVISUAL}

A produção audiovisual - o cinema e, particularmente, a televisão - é um caso exemplar e se constitui num dos setores mais sólidos da economia da cultura. Com relação ao cinema, a sua expansão começou nos anos 30 nos Estados Unidos, durante a recessão provocada pela queda da bolsa em 1929. No final da década, a indústria cinematográfica já havia se transformado na 14ํㅗ dos Estados Unidos em volume e na 11aㅡ em patrimônio, sendo que na ocasião existiam mais cinemas (15.115) do que bancos no país (14.952).

Inicialmente o boom da indústria cinematográfica foi um fenômeno identificado com os grandes estúdios de Hollywood. Após o final da Segunda Guerra Mundial, emergiram novos pólos cinematógráficos, em diferentes países, que, apesar de apoiados em bases indústriais pouco sólidas, conseguiram um impacto cultural muito forte, vindo a redirecionar não apenas os caminhos da produção e da linguagem cinematográficas, mas também o papel do cinema enquanto produção cultural no mundo contemporâneo. Podem ser citados como exemplares o cinema neo-realista italiano, logo após a guerra, a nouvelle vague francesa e o cinema novo no Brasil. A maior parte dos governos não ficou insensível ao potencial cultural explosivo desses produtores emergentes, dando-se conta também que um movimento apoiado em bases culturais tão frágeis não teria condições de ir adiante sem o respaldo de subsídios do Estado.

Paralelamente, ocorreu um outro fenômeno, que foi a expansão da indústria televisiva, com o preço dos aparelhos domésticos tornando-se cada dia mais acessível, configurando-se no novo campo audiovisual como uma ameaça à indústria cinematográfica. Na França, desde o início da década de 70, o Estado passou a intervir gradativamente no setor. Depois dos anos 80, com a expansão das televisões comerciais francesas, multiplicaram-se os núcleos de pesquisa em torno da questão, que passaram a se constituir numa das bases da construção de um projeto de políticas públicas na área.
No livro Cinema, Estado e lutas culturais, anos 50/ 60/70 (Ortiz Ramos, 1983), é enfocado o início desse processo no Brasil, com a criação da Embrafilme, no final dos anos 60, e seu desenvolvimento pleno na década de 70. O cinema brasileiro chegou a produzir 100 filmes em 1978 e ficou na faixa de 80 a 100 filmes nos anos 80, indo à bancarrota com a chegada de Collor à Presidência do país, que praticamente extinguiu o aparato de fomento estatal. Na França, até hoje o Estado mantém apoio ao cinema, que vem conseguindo, durante toda a década de 90 , ocupar cerca de $30 \%$ a $40 \%$ do mercado, enfrentando seu principal opositor que é, obviamente, os Estados Unidos (Documentation Française, 1998).

Na Europa presenciou-se - desde 1995, mas com mais intensidade a partir de 1997 - uma verdadeira revolução no campo da produção cinematográfica, através das televisões privadas, na tentativa de fazer frente às produtoras norte-americanas, transformando-se nas principais agentes do cinema europeu contemporâneo. Itália, França, Alemanha, Espanha e Reino Unido - nesta ordem - são os pólos cinematográficos mais beneficiados por essa ação. A parceria entre cinema e televisão na Europa não é nova. Ela surgiu na década de 70 , por uma determinação das políticas culturais nacionais, visando a proteção das indústrias cinematográficas locais. No entanto, foi apenas nas últimas duas décadas, através das cadeias privadas, numa política de consolidação da indústria audiovisual européia, que essa relação veio assumir grandes proporções, transformando a televisão numa parceira fundamental do cinema. O canal + $(P l u s)$ francês aparece como o mais importante agente desse processo, tendo sido responsável pela realização de 108 produções cinematográficas, em 1997, e 111, em 1998 (Le Monde, junho de 1999). Embora o parque cinematográfico europeu fique com a maior fatia dos investimentos, a atuação do canal + é mais desterritorializada, sendo que algumas produções brasileiras já vêm se beneficiando com ela. Um exemplo é o filme dirigido por Walter Salles, "O primeiro dia", que foi uma produção da televisão francesa. Paralelamente, o Estado francês, ancorado em instituições como o CNC (Centre National de la Cinematographie), o INA (Institut National de l'Audiovisuel) e o CSA ( Conseil Supérieur de L'Audiovisuel), que atuam simultaneamente como núcleos de pesquisa e agências de fomento à produção, vem desempenhando um papel fundamental no desenvolvimento da indústria cinematográfica francesa.

Boa parte dessa nova geração de pesquisadores pode contar com recursos vultosos que lhes possibilitaram a 
produção de trabalhos que revolucionaram o campo de estudos da cultura, porém, procurando sempre preservar com relação à abordagem um enfoque crítico. Armand Mattelart (1999:20-2) enfatiza que o objetivo de realizar um balanço crítico atravessa todos os projetos na área do audiovisual, sendo que a produção do Ministério da Pesquisa e da Tecnologia - envolvendo pesquisadores do CNRS, das Universidades e do INA - é reveladora dessa preocupação. Nessa geração desponta, entre os pioneiros e como inovador, Michel de Certeau (1980), que, através de seu trabalho tematizando as "artes de fazer", redimensionou os estudos sobre recepção, retirando-os do impasse construído pelas teorias funcionalistas. Richard Hoggart (1975), um dos fundadores dos Cultural Studies, também é figura fundamental na concretização desses estudos, com a obra precursora As utilizações da cultura, cuja primeira edição é de 1957. Contudo, Armand Mattelart observa que o "enfoque precoce sobre os receptores nas análises de Hoggart não impedem que suas hipóteses permaneçam profundamente marcadas pela desconfiança face à industrialização da cultura. A própria idéia de resistência das classes populares que sustenta a aproximação das práticas culturais das mesmas está ancorada nesta crença." (Mattelart e Neveu, 1996:17).

Ainda em relação às indústrias culturais, não pode deixar de apontar que elas já atraíram a atenção até mesmo de um sociólogo do porte de Pierre Boudieu. Em 1974 Bourdieu enfocou as empresas de jornalismo em um artigo na revista Actes de la recherche en sciences sociales. Posteriormente publicou um pequeno livro, já traduzido para o português em 1997, com o título Sobre a televisão (Bourdieu, 1997). Pode-se citar, na discussão sobre "informação e comunicação", a recente entrevista de Armand Mattelart (2001) - professor de l'Université Paris VIII -, na qual menciona uma "outra" sociedade de informação, que poderia beneficiar uma maioria.

Aqui, concentra-se a abordagem na França, onde essa relação entre Estado, mercado e pesquisa acadêmica é muito forte, dando origem a esse modelo de organização que fortaleceu a indústria cultural francesa e a vem tornando competitiva no contexto globalizado. O objetivo da pesquisa realizada no espaço francês foi elaborar uma análise que estabelecesse um contraponto com a história e a organização do contexto brasileiro. No entanto, é inevitável, e impossível, qualquer abordagem da indústria audiovisual no segundo milênio sem se referir à produção norte-americana, que ainda permanece como uma referência forte no espaço globalizado, com a qual as demais produções têm necessariamente que se defrontar.

\section{ARTE CONTEMPORÂNEA}

No caso da arte contemporânea, presenciou-se, no pósguerra, um fenômeno análogo ao que ocorreu no cinema e em outras esferas culturais, com uma multiplicação de campos de produção fortes em vários países do mundo. A Arte Povera italiana e o neoconcretismo no Brasil são alguns produtos desse movimento, que no domínio da arte contemporânea têm um caráter complicador, em virtude da repercussão extremamente restrita dessas produções. Nos países ricos os setores público e o privado se deram conta, desde os anos 60 , que, sem o suporte de uma política cultural muito bem articulada, este campo de produção não teria condições de sobreviver.

Antes de se avançar nesta análise, é necessário definir o que se compreende por arte contemporânea. Muito mais do que um critério de periodização, o termo é utilizado para identificar um segmento específico da produção artística atual. Nem toda arte produzida hoje pode ser classificada como contemporânea. A designação é atribuída à produção de artes plásticas que começou a se desenvolver depois da Segunda Guerra Mundial, tornando-se visível a partir da década de 60. Assumindo configurações muito diferenciadas, que culminam em repertórios teóricos e materiais muito distintos, tende sempre a estabelecer uma conexão estreita com a tradição artística ocidental. Isto não significa que a arte contemporânea seja um produto ou uma evolução da história da arte. É certamente informada por ela. Porém, a história da arte, neste caso, é antes de tudo um canal através do qual um grupo de artistas estabelece conexão com um mundo da arte específico e com o qual desejam ver os seus trabalhos identificados. Para Nathalie Heinich (1998a), trata-se de um gênero da arte atual - como foram, em outras épocas, a pintura histórica e a pintura de paisagens - e, da mesma forma que todo gênero, tem como principal finalidade organizar a produção no mercado.

O mundo da arte contemporânea é um espaço internacionalizado, gerido pelas redes de galerias e de instituições, em que a participação das instituições nos últimos anos vem se revelando cada vez mais preponderante. A partir da década de 80 , as fronteiras deste espaço têm se mostrado cada vez mais fluídas, sendo que o número de produções que circulam em seu interior está se ampliando consideravelmente (Zolberg e Cherbo, 1997). 
A base do circuito contemporâneo surgiu no início do século XX, a partir da arte moderna. Na passagem de uma produção para outra, registrou-se uma mudança na dinâmica de operação do universo. O campo da arte moderna organizava-se como uma esfera de bens restritos, de fronteiras muito delimitadas, em que predominava uma cultura de iniciados (Bourdieu, 1996), pontuada por um mercado de elite que girava em torno dos colecionadores particulares (Moulin, 1967).

O pós-guerra assinalou uma ampliação considerável do mundo das artes plásticas em escala internacional, que está vinculado ao desenvolvimento de um sistema de comunicação mundo, passando a se converter num eficiente veículo de divulgação da produção cultural de um modo geral. A expansão da cultura nos anos 60 está relacionada com esse processo. Neste novo contexto, as artes plásticas se consolidam, operando a partir de um novo regimento: o da comunicação, muito diferente do sistema de consumo restrito da arte moderna, no qual "a realidade da arte contemporânea constrói-se fora das qualidades próprias da obra, na imagem que ela suscita nos circuitos de comunicação" (Cauquelin, s.d.). A partir de então, assinalam-se duas transformações importantes nesse domínio. Primeiramente, neste novo modo de operação, a cultura de exposição vem se afirmando cada vez mais como a principal vocação da arte contemporânea. No contexto atual, o mercado privado de colecionadores passa adquirir um caráter secundário, à medida que a produção contemporânea, obedecendo a mesma lógica presente nos cinemas e nas salas de concerto, torna-se objeto de um consumo puramente simbólico, com o espectador pagando um ingresso para ver a exposição, mas sem deter a propriedade privada das obras. Em seguida, e em conseqüência desta transformação, na proporção em que a globalização se consolida, as artes plásticas passam a operar na esfera da indústria cultural (Huyssen, 1997). As mostras de artes plásticas, a partir da década de 80 , convertem-se, cada vez mais, em acontecimentos midiáticos, envolvendo o trabalho de muitos profissionais e tendo como objetivo o grande público (Selbach, 2000). Atualmente, por exemplo, o custo de uma grande exposição é equivalente ao de uma produção cinematográfica de porte, sendo que o público e as receitas obtidas nas duas categorias de eventos também se equiparam (Bueno, 1999).

No entanto, arte moderna e arte contemporânea são ambas produtos do ciclo da modernidade que se inicia no século XIX e apresentam alguns traços característicos em comum: estão constantemente transgredindo os critérios artísticos estabelecidos, uma vez que elas não se pautam mais pelas normas da história da arte (Belting, 1987) e sempre foram objetos de rejeição sistemática pelo público (Heinich, 1998b). Se, no mundo da arte moderna, a sua impopularidade se constituía como um valor - reforçando o caráter elitista de seu campo -, no contexto da arte contemporânea ela se converteu num obstáculo (Bueno, 1999). Este problema é superado com a criação de um sistema de mediação que ajuda a decifrar o segredo, colocando a produção ao alcance do público. Nathalie Heinich (1998a) considera que este é o triplo jogo que marca o modus operandi da arte contemporânea: a transgressão das fronteiras da arte pelos artistas; as reações negativas do público; e a integração da produção a partir da intermediação de instituições e especialistas. Este triplo jogo é um dos componentes responsáveis pelas constantes redefinições no conceito de arte corrente e também pelo movimento de ampliação dos domínios do mundo da arte.

Tendo em vista que a circulação da arte contemporânea só se concretiza a partir do desvendamento da produção para o público, a construção da recepção passou a ser um elemento fundamental na organização de seu universo. Na esfera restrita do mercado de arte moderna, o marchand e o crítico realizavam essa operação junto aos diretores de museus e colecionadores. No contexto atual, com as instituições artísticas funcionando como ramos da indústria cultural, voltadas para um público ampliado, este empreendimento revelou-se não apenas mais custoso, como também mais complexo. Na sociedade globalizada, essa integração gradativa da produção artística contemporânea, e da cultura de um modo geral, vem se consolidando nos países ricos a partir de um modelo de operação que se desenvolve entre o mercado e o Estado.

Contrariando algumas leituras rápidas do processo de globalização, nas décadas de 70 e 80 a participação e a intervenção do Estado na economia e na organização da cultura apresentou um crescimento sem precedentes. Podem ser citadas, como casos exemplares, a implantação de uma política para a recuperação e a reorganização dos museus de arte na Europa e nos Estados Unidos (Dimaggio, 1986; Pommerehne e Frey, 1993) - que durante a década de 60 encontravam-se praticamente arruinados - , além da criação de importantes fundos para as artes, como o National Endowment for the Arts, em 1965, nos Estados Unidos (Crane, 1987; Zolberg, 1997), e os Fonds d'Intervention Culturelle, em 1971, na França (Moulin, 1992). Estes aparelhos atendem a uma dupla finalidade: fornecer subsídios básicos para que a produção possa 
materializar-se, provendo suporte à sua circulação e à sua recepção.

A produção da arte contemporânea implica, geralmente, um empreendimento de alto custo, pois inicialmente, sua concretização envolve um projeto de elaboração e execução de longa duração e, depois, a realização deste projeto abarca um capital considerável, porque os materiais envolvidos, na maior parte das vezes, embora muito diversos, são caros (ferro, concreto, computadores, vídeos, etc.) e, em outras ocasiões, embora de pequeno custo, envolvem uma coleta longa e trabalhosa (como talheres de companhias aéreas, sacolas plásticas de museus, sapatos velhos, cascas de ovos, vestidos de noiva, etc.). No caso das performances, estas podem depender de uma mobilização intensa dos meios de comunicação. Dependendo do projeto, surgem outras variantes que pesam, como serviços de terceiros, muitos deslocamentos, longas filmagens e até negociações com as autoridades políticas, que se estendem por anos, como é o caso dos trabalhos do artista plástico búlgaro, Christo, que estabelecem quase sempre uma relação com monumentos públicos em diferentes cidades do mundo.

O mundo da arte contemporânea já extrapolou há muito tempo o universo da pintura e da escultura, muito embora elas ainda permaneçam como parte dele, ressurgem com uma outra apresentação mais sintonizada com as expressões do repertório de comunicação da época em que vivemos. Em suma, as artes plásticas contemporâneas para poderem se realizar plenamente necessitam do apoio de recursos substanciais, que possibilitem não apenas sua recepção e circulação, mas também sua produção.

No caso das artes plásticas, na base desta ampliação estão as novas políticas culturais responsáveis pela redefinição das instituições, que passaram de redutos de uma cultura de elite para atuar como espaços da cultura de massa. A repercussão das exposições de arte organizadas em São Paulo por ocasião dos 500 anos da descoberta do Brasil é um exemplo desse fenômeno globalizado que se estende, ainda de forma errática, ao contexto cultural brasileiro. Em muitos países presencia-se a intervenção do Estado nesse processo, gerando pólos de pesquisa fortes que alimentam projetos culturais, cuja principal finalidade vem sendo impedir que esta expansão da cultura corra ao sabor do mercado e à deriva dos fluxos globalizados (Moulin, 1967). É o suporte desses projetos o responsável pela viabilização e pelo fortalecimento de algumas produções em detrimento de outras no circuito globalizado. Cabe aqui mencionar os trabalhos pioneiros de Bourdieu e Darbel (1969), encomendado pela Associação Européia dos Museus de Arte, e de Moulin (1967), publicados ainda na década de 60, assinalando o início de uma parceria entre o campo acadêmico e os projetos públicos, que permanece como um dos traços característicos da gestão cultural na França contemporânea, mas que está presente também na comunidade européia em geral (Documentation Française, 1987), nos Estados Unidos e no Canada. É importante enfatizar que, muito embora a partir da década de 90 tenham surgido facções políticas em diferentes países, questionando a extensão do apoio do Estado à cultura e às artes, esse debate se dá num momento em que estes universos já se encontram consolidados (Zolberg, 1996; Telerama, 2000a e b).

Sendo assim, o modelo de organização das artes plásticas contemporâneas, implantado na França e nos Estados Unidos, não apenas respaldou a sua constituição num campo de pesquisa, como também continua evoluindo até hoje fundamentado nele. No Brasil, está se iniciando, tardiamente, um esforço de pesquisa ainda para tentar mapear esse universo.

\section{NOTAS}

E-mail dos autores: jmortizramos@uol.com.br e buenow@ig.com.br

O presente texto é uma explanação inicial elaborada a partir de uma pesquisa realizada em 2000, em Paris, na École des Hautes Études en Sciences Sociales/ Centre des Recherches sur le Brésil Contemporain, cujos dados ainda estão sendo processados. Neste projeto, José Mario Ortiz Ramos contou com o apoio de uma bolsa de Pesquisa no Exterior, da Fapesp.

1. No Brasil, em 1995, os gastos públicos com a cultura representaram 0,089\% do PIB e um total de 692 milhões de reais (Fundação João Pinheiro, 1998).

\section{REFERÊNCIAS BIBLIOGRÁFICAS}

BELTING, H. L'Histoire de l'art est-elle finie? Nîmes, Jacqueline Chambon, 1987. BOURDIEU, P. As regras da arte. São Paulo, Cia. das Letras, 1996.

$$
\text { Sobre a televisão. Rio de Janeiro, Zahar, } 1997 .
$$

BOURDIEU, P. e DARBEL, A. L'amour de l'art. Les musées d'art européens et leur public. Paris, Minuit, 1969.

BUENO, M.L. Artes plásticas no século XX. Modernidade e globalização. Campinas, Ed. da Unicamp/Fapesp, 1999.

CANCLINI, N.G. Culturas híbridas. São Paulo, Edusp, 1997.

CASTELLS, M. A sociedade das redes. São Paulo, Paz e Terra, 2000.

CAUQUELIN, A. A arte contemporânea. Porto, RÉS-Editora, s.d.

CERTEAU, M. L'Invention du cotidien. Arts de faire. Paris, Unin Générale d'Éditions, v.1, 1980.

CRANE, D. The transformation of the avant-garde - The New York art world 1940-1985. Londres/Chicago, University of Chicago Press, 1987.

DIMAGGIO, P. Nonprofit interprises in the arts. Nova York/Oxford, Oxford University Press, 1986.

DOCUMENTATION FRANÇAISE. Mecenat en Europe. Paris, 1987. 
. Indicateurs statistiques de l'audiovisuel: cinéma, télévision, vidéo edition 1998. Paris, 1998.

DOMÍNGUEZ, I. e MORATÓ, A. Arte, cultura y sociedad. Barcelona, Aesca, 1991.

FUNDAÇÃO JOÃO PINHEIRO. Diagnóstico dos investimentos em cultura no Brasil. Belo Horizonte, nov. 1998.

GIDDENS, A. As conseqüencias da modernidade. São Paulo, Unesp, 1990.

HEINICH, N. Le triple jeu de l'art contemporain. Paris, Minuit, 1998a.

. L'art contemporain exposé aux rejets. Nîmes, Jacqueline Chambon, $1998 \mathrm{~b}$

HOGGART, R. As utilizações da cultura. Lisboa, Presença, 1975.

HUYSSEN, A. Memórias do modernismo. Rio de Janeiro, UFRJ, 1997.

LE MONDE. "Les télévisions, maillon fort du financement du cinéma européen". Paris, 13/05/1999.

"Le financement des films français en pleine révolution". Paris, 13/05/1999.

MATTELART, A. Comunicação mundo - História das idéias e estratégias. Petrópolis, Vozes, 1994.

. "Une étape decisive: le rapport, Mattelard/Stourdzé" (entrevista com A. Mattelart). Dossier de l'audiovisuel, n.85, maio-junho 1999.

. "Un autre societé de l'information est possible" (entrevista). Le Monde Interactif - Le Monde, 28/03/2001.

MATTELART, A. e NEVEU, E. “'Cultural Studies' stories. La domestication d'une pensée sauvage?" Reseaux, n.80, nov./dez 1996.
MATTELART, A. e STOURDZÉ, Y. "Technologie, culture et communication, rapport au ministre de l'industrie". Paris, La Documentation Française, 1982.

MIÉGE, B. "L'evolution des médias confrontés à la recherche”. Dossier de L'audiovisuel, n.85, maio-jun. 1999.

MOULIN, R. Le marché de la peinture en France. Paris, Minuit, 1967. . L'artiste, l'institution et le marché. Paris, Flammarion, 1992.

ORTIZ RAMOS, J.M. Cinema, Estado e lutas culturais, anos 50/60/70. Rio de Janeiro, Paz e Terra, 1983.

. Televisão, publicidade e cultura de massa. Petrópolis, Vozes, 1995.

PINEAU, G. (org.). Dossier: "La recherche en information et communication en France". Dossiers de L'audiovisuel, n.85, maio-jun. 1999.

POMMEREHNE, W. e FREY, B. La culture a-t-elle un prix? Essai sur l'economie de l'art. Paris, Commentaire/Plon, 1993.

SELBACH, G. Les musées d'art americaines: une industrie culturelle. Paris, L'Harmattan, 2000.

TELERAMA. Dossier "L'argent de la culture", n.2.653, nov. 2000a, primeira parte. parte.

Dossier: "L'argent de la culture", n.2.654, dez. 2000b, segunda

ZOLBERG, V. "Paying for art: the temptations of privatization à l'americaine". International Sociology, v.11, n.4, dez. 1996.

. "Cultura de Nova York: ascendente ou descendente?" Cultura Vozes, n.3, v.91, maio-jun.1997.

ZOLBERG, V. e CHERBO, J.M. Outsider art. Contesting bounderies in contemporary culture. Cambridge University Press, 1997. 